\title{
ATENUADORES E INTENSIFICADORES EN LAS PETICIONES DE CHINOS $Y$ ESPAÑOLES: PROPUESTA DE ESTUDIO
}

\author{
DOWNGRADERS AND UPGRADERS IN CHINESE AND SPANISH REQUEST: A \\ RESEARCH PROPOSAL
}

\author{
María Querol Bataller \\ Universidad Católica de Valencia San Vicente Mártir
}

RESUMEN:

Todavía son escasas las investigaciones de pragmática intercultural que abordan explícitamente las diferencias, o similitudes, entre los usos pragmáticos y comunicativos del chino y del español. Este hecho motiva la realización de interpretaciones de forma indirecta a través de los estudios realizados en relación a otras lenguas, en los que no siempre las variables consideradas son idénticas. La investigación en la que se incluye este trabajo trata de paliar dicha carencia. No obstante, en este marco reducido se tratará específicamente el siguiente aspecto: el uso de atenuadores e intensificadores por parte de chinos y españoles en las peticiones. Para ello adoptamos la metodología que inicialmente proponen Blum-Kulka y otros (1989), por tanto, el instrumento utilizado fue a Discourse Completion Test. Por otra parte, la nómina de recursos valorados en el análisis de los corpus atiende, por una parte, a la idiosincrasia de las lenguas objeto de estudio y, por otra parte, a las realizaciones concretas que realizaron los informantes. En consecuencia, en el análisis del corpus español se tomó como referencia la nómina de recursos atenuadores recogidos en Albelda y Cestero (2011) y Cestero y Albelda (2012); y para el análisis del corpus chino los recogidos en Blum-Kulka y otros (1989) y Zhang (1995a). Con respecto a los intensificadores, para el análisis del corpus español se tomó como referencia la propuesta de Albelda (2007), y para el análisis del corpus chino fueron los recursos recogidos en Blum-Kulka y otros (1989) y Zhang (1995a) los considerados.

PALABRAS CLAVE: petición, atenuador, intensificador, español, chino
Abstract:

Research about differences or similarities in Chinese and Spanish pragmatic uses is still an emerging field. As a result of these, for the moment drawing conclusions about this topic requires researches or works which compare Chinese or Spanish with other languages and cultures. However, these researches not always use the same methodology or share the same goals. Therefore, the aim of this research is contribute to ease this situation. In order to do this, this work compares how Chinese people and how Spanish people use downgraders and upgraders in a specific kind of directive speech act, request. The research follows the methodology that was used by Blum-Kulka et al. (1989), Discourse Completion Test. However, the analysis of the corpus has into consideration, on the one hand, the own characteristics of Spanish and Chinese language; and, on the other hand, the resources truly used by the informants that took part into this research. Therefore, downgraders considered for the analysis of Spanish corpus were taken from Albelda and Cestero (2011) and Cestero and Albelda (2012), and for the Chinese corpus from BlumKulka et al. (1989) and Zhang (1995a). In the same way, upgraders considered for the analysis of Spanish corpus were taken from Albelda (2007), and for the Chinese corpus from Blum-Kulka et al. (1989) and Zhang (1995a).

Key words: request, downgraders, upgraders, Spanish 


\section{INTRODUCCIÓN}

Briz (1998: 145) caracteriza los atenuantes como una especie de reguladores de las máximas de cooperación (Grice, 1975), especialmente la del tacto, la de la modestia y la de la unanimidad, "cuya función podría concretarse todavía más en la minorización del beneficio del que habla, minorización de su contribución y del posible desacuerdo; y consiguientemente, en la maximización en la relación con el interlocutor; más aún si no existe relación de solidaridad entre los interlocutores». (Briz, 1998: 145) Además, Briz (1998) señala que el uso de los atenuadores no se vincula únicamente a una función cortés, sino también a una función dialógica y argumentativa.

Ahora bien, la cortesía [... es es sólo una de las manifestaciones o funciones de los atenuantes [...]: mitigamos o minoramos, des-activamos o des-realizamos lo enunciado o lo por enunciar antes por eficacia que por cortesía; el uso en apariencia cortés es sólo la máscara que esconde el propósito. (Briz, 1998: 145-146)

Así pues, el uso de atenuadores junto a la petición supone la elección de una estrategia pragmática, en la que el hablante trata de reducir el posible efecto negativo del contenido proposicional o de la fuerza ilocutiva del propio acto utilizando una serie de recursos, lingüísticos o paralingüísticos, que «modifican el núcleo de la exhortación, aminorando y suavizando su carácter impositivo» (Ballesteros, 2002). Dicha acción podría tener, al menos, dos fines concretos, por una parte, facilitar el desarrollo sin tensiones de la interacción y, por otra parte, persuadir al oyente de modificar su conducta.

Existen estudios que contrastan el uso que de estos realizan españoles y hablantes de otras lenguas y culturas ${ }^{1}$, aunque la nómina de lenguas y culturas comparadas se reduce, fundamentalmente, a algunas lenguas y culturas occidentales. Quizá uno de los trabajos más relevantes fue el de Blum-Kulka y otros (1989), en el que bajo el epígrafe de internal modifiers ('modificadores internos'²) se comparaba el uso que de los atenuadores, léxicos y sintácticos, y de los intensificadores realizaban estudiantes de universidades australianas, estadounidenses, inglesas, canadienses francófonas, danesas, alemanas y hebreas en el acto de habla de las peticiones. Las conclusiones, referidas a lenguas como el inglés australiano, español argentino, francés canadiense y hebreo, muestran que las diferencias interlingüísticas se basan no solo en la elección del recurso utilizado, sino también en su forma de uso y en su función. Se concluye afirmando que los hablantes ingleses utilizan los recursos atenuantes en las peticiones convencionalmente indirectas con el doble de frecuencia que los hablantes francófonos canadienses y hebreos, y que, por otra parte, los

\footnotetext{
${ }^{1}$ Cestero y Albeda (2012) señalan que, aunque el estudio de la atenuación ha experimentado un desarrollo considerable en las últimas décadas, dicho desarrollo no ha tenido la misma profusión en lo que se refiere al español, especialmente en la relación entre atenuación y factores sociales. Y precisamente con el fin de mejorar dicha situación se inició el proyecto ES.VAR.ATENUACIÓN (“La atenuación pragmática en el español hablado: su variación diafásica y diatópica”).

2 "elements within the request utterance proper (linked to the Head Act), the presence of which is not essential for the utterance to be potentially understood as a request. [...] Such modifiers can be multifunctional in two distinct ways. First, they may act both as indicating devices, used to signal pragmatic force, as well as sociopragmatic devices, meant to affect the social impact the utterance is likely to have. [...] Second, in their sociopragmatic role, the may act either as downgraders, meant to mitigate, (soften) the act or alternatively as upgraders that emphazise its degree of coerciveness. (Blum-Kulka et al., 1989:19)
} 
hablantes de español argentinos son los que menos los utilizan (Blum-Kulka y otros, 1989: 61-62).

Posteriormente, Ballesteros (2002) y Díaz (2003), entre otros, han contrastado, siguiendo la misma metodología, el uso específico que de estos realizan españoles y británicos. Como se observa en las citas seguidamente reproducidas, ambos alcanzan unas conclusiones muy similares.

Los atenuantes léxicos y frasales son utilizados con mayor frecuencia por los nativos británicos que por los españoles. [...] Los atenuantes más frecuentes en español son las fórmulas de cortesía (41.53\%) y las fórmulas de asentimiento (26.15\%). Por su parte los mecanismos más utilizados por los británicos han sido las expresiones de cortesía (29.70\%) y las mitigaciones (20.79\%). [...] El número de atenuantes sintácticos es superior al de atenuantes léxicos encontrados llegando a acompañar al $52.77 \%$ del total de 180 actos emitidos en español y al $99.44 \%$ de los 180 actos emitidos en inglés. [...] La variedad de atenuación sintáctica predominante es la que se basa en la presentación hipotética de los hechos, y lo es en ambas sociedades con 66 y 101 casos en español y en inglés respectivamente. (Ballesteros, 2002)

los hablantes nativos de inglés, el 97,3 \% de las peticiones (363 de 373) presenta algún modificador sintáctico. El porcentaje de peticiones producidas por hablantes nativos de español que contiene algún modificador sintáctico es del 88,9 \% [...] La categoría más frecuente [...] es aquélla que representa la combinación de una estructura interrogativa y una forma verbal condicional. [...] Mientras que los nativos de inglés emplean algún mitigador léxico o frasal en el $78 \%$ de los casos, en los hablantes de español este porcentaje se reduce al $54,3 \%$. [...] mientras que el tipo más frecuente en las peticiones producidas por los informantes de los grupos I-hablantes nativos de inglés-y III-hablantes no nativos de inglés- es el 1, marcador de cortesía, con 24,4 \% y 29,5\% respectivamente, en el grupo II -hablantes nativos de español- este tipo de mitigador, con un 19,0 \%, ocupa el segundo lugar tras el tipo 0, o ausencia de mitigador. (Díaz, 2003: 253-258)

Siebold (2008), en cambio, contrasta el uso que de mitigadores léxicos y sintácticos realizan en las peticiones españoles y alemanes.

En lo que a los mitigadores léxicos se refiere, observamos semejanzas en el uso de los marcadores de cortesía ${ }^{4}$, como bitte o por favor, cuyo porcentaje es parecido en español (14\%) y en alemán (17\%). Ahora bien, el uso de los

\footnotetext{
${ }^{3}$ Hemos seleccionado los datos referidos únicamente a las peticiones, pues Díaz (2003) analiza también la presencia de estos recursos en otros actos de habla -la petición de disculpa, la expresión de agradecimiento y la queja-.

${ }^{4}$ Llegados a este punto conviene realizar algunas precisiones en relación al término "cortesía". Puede usarse en un sentido tradicional, «vinculado al uso de muestras de respeto o deferencia cuyo uso determina y exige la organización social» (Escandell, 1995: 32); o puede también considerarse según una concepción estratégica, es decir, "como fruto de la necesidad humana de mantener el equilibrio en las relaciones interpersonales y su manifestación externa sería el conjunto de "maniobras lingüísticas" de las que puede valerse el hablante para evitar o reducir al mínimo el conflicto con su interlocutor cuando los intereses de ambos no sean coincidentes.» (Escandell, 1995: 33). En esta investigación prevalecerá esta última concepción del término, por tanto, el uso de marcadores de cortesía como por favor se entiende como una de esas "maniobras lingüísticas", aunque no la única, de las que se vale el hablante para los fines antes expuestos.
} 


\section{normas}

Atenuadores e intensificadores en las peticiones de chinos y españoles | María Querol

minimizadores, los reductores y los marcadores interpersonales diverge considerablemente entre ambas lenguas. En español no se ha registrado ningún empleo de minimizadores o reductores. En contraste con esto, se emplean distintos tipos de minimizadores $(21 \%)$ y de reductores $(8 \%)$ en alemán. [...] En cuanto a los marcadores interpersonales, en cambio, podemos observar que no se usan en ninguna petición alemana, pero sí en algunas (9\%) españolas. [...] Las diferencias registradas por lo que se refiere a los mitigadores sintácticos son llamativas sobre todo en el empleo del condicional o del subjuntivo (Konjunktiv) para suavizar la fuerza impositiva de la petición. (Siebold, 2008: 102-104)

Con respecto al chino, uno de los trabajos más relevantes, y que sigue fielmente la metodología de Blum-Kulka y otros (1989), fue el de Zhang (1995a, b). En este se muestra como los hablantes chinos evidencian una clara preferencia por el uso de atenuadores léxicos en detrimento de los atenuadores sintácticos - quizá porque una de las estrategias preferidas por los hablantes chinos para realizar peticiones son las oraciones interrogativas -.

Desde el punto de vista comparativo, existen algunos trabajos que contrastan el uso que de atenuadores e intensificadores realizan hablantes chinos y, en la mayor parte de los casos, hablantes anglófonos. Por ejemplo, Li (2015) examina el efecto de las variables poder social (+/-P) y rango de imposición (+/-R) en la selección de modificadores, internos y externos, utilizados en las peticiones realizadas vía e-mail por hablantes chinos y australianos. Así, con respecto a los atenuadores, aprecia una estrecha vinculación entre su uso y las variables sociales que examina; en concreto, en tres de las cuatro situaciones contempladas (+P, -R; -P, +R; +P, +R), los hablantes chinos, a diferencia de sus homólogos australianos, utilizaban con mayor frecuencia dos tipos de atenuadores expresiones de cortesía y subjetivizadores - y solo en la situación descrita como $(-P,+D)$ preferían el uso de cuantificadores minimizadores y apeladores. Otra singularidad de los hablantes chinos que observa Li (2015) es que en las situaciones (-R) el uso de marcadores de cortesía y subjetivizadores se incrementa notablemente a medida que la relación entre los interlocutores es más asimétrica.

Hong (1998), que compara la realización de peticiones por parte de hablantes alemanes y chinos, concluye que estos últimos usan con mayor frecuencia que sus homólogos alemanes los modificadores léxicos o frasales, que prefieren los sintácticos. No obstante, existe una excepción. Según Hong (1998), en las situaciones en las que el que realiza la petición tiene menor poder no halla dichas diferencias.

The major findings were that in the relationship of high to low status, Chinese speakers use more lexical /phrasal modifications, whereas more syntactic modifications were applied by German Speakers. Among those of equal status, Chinese appeared to be more polite than Germans by using more supportive moves and lexical / phrasal modifications. Interestingly, in the relationship of low to high status, there was no difference in the use of syntactic and lexical/phrasal modification between Chinese and Germans. (cit. en Rue y Zhang, 2008: 30) 
Más recientemente, en la comparación que realizan Rue y Zhang $(2008)^{5}$ sobre el uso de las estrategias de petición que realizan hablantes chinos y coreanos, se observa que los primeros prefieren, al menos de forma cuantitativa, el uso de cuantificadores minimizadores honoríficos y downtoner (partículas atenuadores usadas al final de la oración para minimizar el impacto de la petición) como atenuadores léxicos. Con respecto al uso de atenuadores sintácticos, constatan, comparativamente con sus homólogos coreanos, una mayor frecuencia de uso de las oraciones interrogativas, excepto en las situaciones familiares, en las que se prefiere la reduplicación del verbo.

Análogamente a la caracterización realizada para los atenuadores, Briz (1998: 114) vincula el uso de los intensificadores al realce de algunas de las máximas de cooperación de Grice (1975), especialmente la de cualidad y pertinencia. Refiriéndose específicamente al uso de esta categoría en las peticiones, Blum-Kulka y otros (1989: 285) definen los intensificadores como elementos cuya función es la de aumentar el impacto de la petición. Dicho uso debe de tener como fin intentar persuadir al oyente de modificar su conducta en la dirección deseada por el hablante. Nuevamente se recurre para ello a recursos lingüísticos y paralingüísticos, que pueden incidir sobre el enunciado o sobre la enunciación (Briz, 1998; Albelda, 2007\%). Dicho esto, parece que todavía no existe una concepción clara y uniforme del fenómeno de la intensificación, tal y como se observa, por ejemplo, en la revisión bibliográfica que realiza Albelda (2007) ${ }^{7}$. Quizá por ello los estudios contrastivos con respecto a la intensificación constituyen una nómina mucho más reducida. Por ejemplo, en el trabajo de Blum-Kulka y otros (1989) no aparecen referencias explícitas referidas al español en el estudio de esta cuestión. En los trabajos de Díaz (2003) y Siebold (2008: 102) antes mencionados tampoco se estudia esta categoría en las peticiones. «En nuestro corpus no hemos encontrado ningún ejemplo de modificación interna a través de un intensificador» (Siebold, 2008: 102), quizá porque en ambas investigaciones el uso de intensificadores debía constatarse en el núcleo de la petición. Escandell (2004: 187-188), sin embargo, considera que mitigadores e intensificadores pueden aparecer tanto en el núcleo como en los apoyos de la petición ${ }^{8}$.

En relación con el uso que de los intensificadores realizan los hablantes chinos, Zhang (1995a: 56) indica la poca frecuencia con que este recurso es utilizado. De hacerlo, son los que denomina "intensificadores de tiempo" los que tienen un mayor uso, especialmente en peticiones realizadas entre iguales. Li (2015) muestra que los hablantes chinos prefieren

\footnotetext{
${ }^{5}$ La investigación de Rue y Zhang (2008) no utiliza como método discursion completion test, sino role-plays y la grabación de conversaciones.

${ }^{6}$ Albelda (2007) recoge un extenso y exhaustivo listado de mecanismos para intensificar el enunciado o la enunciación, que se basa, fundamentalmente, en la distinción de niveles lingüísticos y categorías gramaticales.

${ }^{7}$ En el presente trabajo se incluyen dentro de la categoría de intensificadores aquellos recursos lingüísticos que el hablante utiliza intencionadamente para incrementar la cualidad o la cantidad, en un grado mayor que el positivo, aunque no necesariamente en el máximo, de un determinado elemento del contenido proposicional o de la enunciación. Dicho incremento, además, no ha de responder necesariamente a la "verdad de los hechos referidos", sino que se trata de un mecanismo de cortesía estratégica para lograr determinados fines comunicativos. "Decir la verdad, toda la verdad, y nada más que la verdad no es un imperativo universal, sino, en todo caso, una norma vigente en algunas sociedades, ...y limitada, además, a ciertas situaciones.» (Escandell, 1995: 46)

${ }^{8}$ Según Escandell (2004: 187-188), la estructura interna de una petición no se compone solo del núcleo, sino que incluye también alertadores y apoyos, cada uno de los cuales a su vez es susceptible de incluir una serie de elementos, entre los que se encuentran atenuadores e intensificadores.

${ }^{9}$ Con dicho término se refieren a frases o expresiones que indican la urgencia de la petición, como por ejemplo 马上 (mashang, 'inmediatamente') o 赶紧 (ganjin, 'apresuradamente') (Zhang (1995a: 56; Rue y Zhang, 2008: 43).
} 


\section{normas}

Atenuadores e intensificadores en las peticiones de chinos y españoles | María Querol

el uso de intensificadores en situaciones en las que el que realiza la petición tiene mayor poder social (+PS), y en estas el tipo más frecuente es un intensificador adverbial, como por ejemplo 我真的很希望... ... ('yo verdaderamente espero que...'), que expresa la esperanza de que el receptor cumpla la petición (Li, 2015: 446). Finalmente, Rue y Zhang (2008: 197) señalan la preferencia, tanto de los hablantes chinos como de los hablantes coreanos, por el recurso de la repetición como mecanismo léxico intensificador ${ }^{10}$. Sin embargo, a diferencia de lo que ocurre con los hablantes coreanos, los hablantes chinos los suelen utilizar solo para dirigirse a familiares; es más, Rue y Zhang (2008: 197) concluyen afirmando que los hablantes chinos son bastante cautos en lo que se refiere al uso de intensificadores léxicos que intensifiquen la fuerza ilocutiva de la petición, y solo los utilizan con personas que conocen bien.

Dicho todo esto, el presente trabajo tiene entre sus objetivos principales:

a) describir, comparar y contrastar el uso que de la atenuación realizan los hablantes chinos y españoles en un tipo de acto de habla concreto, la petición

b) describir, comparar y contrastar el uso que de la intensificación realizan los hablantes chinos y españoles en un tipo de acto de habla concreto, la petición

c) atenuar la paupérrima situación que actualmente se constata en los estudios sobre pragmática contrastiva español-chino, chino-español

\section{Metodología}

El instrumento utilizado en esta investigación fue Discourse Completion Test (DCT, en lo que sigue). Varias razones, de carácter teórico y práctico, motivaron tal decisión, algunas de las cuales se exponen a continuación:

a) en Blum-Kulka y otros (1989: 13-14) se considera que mediante el DCT se muestran respuestas estereotípicas, y que esto es lo más adecuado cuando se abordan estudios interculturales

b) la posibilidad de comparar en un futuro los resultados obtenidos en esta investigación con los obtenidos en otras muchas investigaciones ya realizadas con respecto a otras lenguas y culturas, que han seguido la metodología de Blum-Kulka y otros (1989)

c) la dificultad de contar con muestras de habla espontáneas y equivalentes para ambas lenguas. Con respecto al español, sí que existen ya corpus que evidencian el habla espontánea y coloquial de sus hablantes, por ejemplo Val.Es.Co $2.0^{11}$, pero no conocemos un recurso homólogo para el chino, y, aunque así fuera, cabe la duda de si podrían ser considerados equiparables. De igual modo sucede con la utilización de productos

\footnotetext{
${ }^{10} \mathrm{~A}$ diferencia de lo que ocurre con el estudio de los atenuadores, en este trabajo únicamente se valora el uso de los que los autores consideran lexical upgraders (repetition of request, time intensifier y commitment indicator).

${ }^{11}$ Cabedo, Adrián y Pons, Salvador (eds.): Corpus Val.Es.Co 2.0. Recuperado de http://www.valesco.es
} 
audiovisuales como corpus, como por ejemplo, series de televisión chinas y españolas. ¿Podrían considerarse plenamente equivalentes?

Por todo ello, se decidió, al menos en este primer proyecto piloto, utilizar el DCT. En consecuencia, se propuso a los informantes una serie de situaciones sobre las que se les pedía que, después de leer la contextualización, escribieran cuál habría sido su respuesta verbal. Los escenarios escogidos son los mismos que Zhang (1995a, 1995b) utilizó para describir la estrategias de petición en chino; no obstante, de los 10 escenarios contemplados en Zhang (1995a, 1995b) en este trabajo solo se han considerado aquellos que remitían a situaciones en las que los informantes que participaron en esta investigación pudieran haberse encontrado, pues solo así podrían adoptar roles que no les fueran ajenos. Así pues, estos fueron los escenarios presentados:

\begin{tabular}{|c|c|c|}
\hline $\mathrm{S}^{12}$ & Traducción al español ${ }^{13}$ & Traducción al chino ${ }^{14}$ \\
\hline I & $\begin{array}{l}\text { Un estudiante quiere pedir prestados } 100 \text { \$ a su } \\
\text { compañero para comprar una tele. Si tú fueras ese } \\
\text { estudiante ¿qué le dirías a tu compañero? }\end{array}$ & $\begin{array}{l}\text { 学生 }(A) \text { 想向他的朋友借钱15买一 } \\
\text { 台电视机。如果你是那个学生 }(A), \\
\text { 你 会对你的朋友说什么 } 么\end{array}$ \\
\hline$\|$ & $\begin{array}{l}\text { Estudiante (A) a va a visitar a su amigo (B) y quiere } \\
\text { quedarse en la casa de este durante } 2 \text { semanas. El } \\
\text { problema es que su amigo tiene } 3 \text { compañeros de } \\
\text { piso. Si tú fueras el amigo B ¿qué le dirías a tus } \\
\text { compañeros de piso? }\end{array}$ & $\begin{array}{l}\text { 学生 }(A) \text { 去看他的朋友 }(B) 。 \text { 他 }(A) \text { 想 } \\
\text { 在他的朋友 }(B) \text { 家住两个星期。不过 } \\
\text { 他的朋友 }(B) \text { 有三个同屋 }{ }^{16} \text { 。如果你 } \\
\text { 是那个朋友 }(B) \text {, 你 会对你的同屋 } \\
\text { 说什么? }\end{array}$ \\
\hline$|\||$ & $\begin{array}{l}\text { Un estudiante quiere que el profesor modifique la } \\
\text { longitud del trabajo exigido. Si tú fueras el estudiante, } \\
\text { ¿qué el dirías al profesor? }\end{array}$ & $\begin{array}{l}\text { 学生(A)希望他的老师重新规定要他 } \\
\text { 们交的作业篇幅, 希望短一点。如 } \\
\text { 果你是那个学生, 你会对老师说什 } \\
\text { 公? }\end{array}$ \\
\hline $\mathrm{V}$ & $\begin{array}{l}\text { Hace } 5 \text { minutos un cliente A realizó su comanda, pero } \\
\text { ahora ha cambiado de opinión y quiere modificarla. Si } \\
\text { tú fueras ese cliente, ¿cómo llamarías al camarero y } \\
\text { qué le dirías? }\end{array}$ & $\begin{array}{l}\text { 一位顾客点了菜。五分后, 那位顾 } \\
\text { 客改变了主意, 想更改所点的菜。 } \\
\text { 如果你是那位顾客, 你会怎么叫服 } \\
\text { 务员, 你会对服务员说些什么 } \text { 公? }\end{array}$ \\
\hline $\mathrm{V} \| \mathrm{I}$ & $\begin{array}{l}\text { Un estudiante (A) quiere que su compañero de piso } \\
\text { (B) limpie el piso después de la fiesta. Si tú fueras ese } \\
\text { estudiante (A), ¿qué le dirías a tu compañero de piso? }\end{array}$ & $\begin{array}{l}\text { 晚会后, 大学生(A)希望他 的同屋 } \\
\text { (B)打扫场地。如果你是那个学生 } \\
\text { (A), 你 会对你的同屋说什么? }\end{array}$ \\
\hline VIIII & $\begin{array}{l}\text { Estudiante A quiere pedirle los apuntes a estudiante B. } \\
\text { Si tú fueras el estudiante A, ¿qué le dirías al estudiante } \\
\text { B? }\end{array}$ & $\begin{array}{l}\text { 学生 }(A) \text { 想借学生 }(B) \text { 的笔记。如果你 } \\
\text { 是那个学生 }(A) \text {, 你会对学生 }(B) \text { 说什 } \\
\text { 么? }\end{array}$ \\
\hline$x$ & $\begin{array}{l}\text { Huang Ling ha aparcado su coche enfrente de la } \\
\text { entrada de una casa donde recientemente hubo un } \\
\text { incendio. El oficial de policía le pidió a Huang Ling que }\end{array}$ & $\begin{array}{l}\text { 黄良把车停在一幢房子的门前, 这 } \\
\text { 幢房子刚发生过火灾。警察要黄良 }\end{array}$ \\
\hline
\end{tabular}

\footnotetext{
12 La numeración corresponde a Zhang (1995a, 1995b).

${ }^{13}$ La traducción al español de los escenarios propuestos por Zhang (1995a, 1995b) es nuestra.

${ }^{14}$ La traducción al chino de los escenarios propuestos por Zhang (1995a, 1995b) fue revisada por la profesora Elisa Cao Yufei (曹羽菲), colega del departamento de Español de la Universidad de Estudios Internacionales de Shanghái.

${ }^{15}$ En la traducción china no se explicitó la cantidad de dinero, probablemente porque, dadas las importantes diferencias socioeconómicas, la cantidad indicada debía de tener muy diferente consideración en ambos contextos.

${ }^{16}$ En la traducción china se ha utilizado el término 同屋 (tongwu, 'compañero de habitación'), posiblemente con el fin de adaptar la situación originalmente propuesta a la realidad de los informantes chinos que participaron en esta investigación.
} 


\section{normas}

Atenuadores e intensificadores en las peticiones de chinos y españoles | María Querol

\begin{tabular}{|l|l|l|}
\hline & $\begin{array}{l}\text { moviera su coche. Si tú fueras el policía iqué le } \\
\text { habrías dicho a Huang Ling? }\end{array}$ & $\begin{array}{l}\text { 换个地方停车。如果你是那个警 } \\
\text { 察, 你会对黄良说什么? }\end{array}$ \\
\hline$X \mid$ & $\begin{array}{l}\text { Un estudiante quiere que el profesor universitario } \\
\text { amplíe el plazo de entrega del trabajo. Si tú fueras ese } \\
\text { estudiante ¿qué le dirías al profesor? }\end{array}$ & $\begin{array}{l}\text { 一个学生希望他的老师延长交作业 } \\
\text { 对对学生说什么? }\end{array}$ \\
\hline
\end{tabular}

TABLA 1: ESCENARIOS PROPUESTOS A INFORMANTES ESPAÑOLES Y CHINOS, RESPECTIVAMENTE.

Como se observa, los casos propuestos exigen realizar peticiones entre hablantes con relaciones simétricas y también asimétricas en cuanto a poder y distancia social (+/- PS, +/- DS). No obstante, es necesario considerar que, al menos en lo que a poder social se refiere, no existe uniformidad intercultural ni todas las sociedades están igualmente jerarquizadas. Por ejemplo, culturalmente existen divergencias notables en lo que a la relación entre profesor-alumno respecta entre los dos grupos de informantes (Sánchez, 2008).

Para este estudio piloto 35 estudiantes universitarios españoles y 35 universitarios chinos actuaron como informantes. Estos, durante el transcurso de una de sus clases en la universidad, completaron anónimamente, por escrito de forma manuscrita y sin límite de tiempo la tarea que se les pedía.

La vasta difusión del español y del chino hace necesario considerar también las variedades de lengua estudiadas. En este sentido, Briz (2007), atendiendo a sus realizaciones lingüísticas, incluye entre las "culturas de acercamiento" (menos atenuadoras) la española y argentina, y entre las "culturas de alejamiento" (más atenuadoras) la chilena, la mexicana y la venezolana. Es más, las diferencias existentes entre los usos pragmáticos de los hispanohablantes han llevado a Márquez-Reiter y Placencia (2005: 190) a concebir la expresión verbal de la cortesía de los hispanohablantes como un continuum, según el cual argentinos, venezolanos y españoles se situarían en el extremo positivo, uruguayos y chilenos en el centro, y mexicanos, ecuatorianos y peruanos en el extremo negativo. Si esto sucede con respecto al español, podemos atisbar que una situación análoga podría describirse con respecto a los estudios realizados de chino, que en muchas ocasiones se circunscriben a muestras de habla de determinadas regiones y hablantes, pero que no tienen por qué ser extrapolables a toda la comunidad chinohablante. Por todo ello, junto con la respuesta a la situación propuesta se pidió a los informantes que especificaran su edad, sexo, lengua hablada habitualmente en la familia y procedencia geográfica. Así pues, los informantes que participaron en este trabajo presentaban las siguientes características: hablantes jóvenes, todos ellos entre 18 y 25 años, en su mayoría mujeres (m), procedentes del este y sureste de China Continental y de la zona este de España, y cuya lengua habitual en algunos casos no era el español (e) o el chino (ch), sino la lengua o dialecto propio de su zona. En el caso de los informantes españoles, un 65\% afirmaba que utilizaba solo el valenciano (val), lengua cooficial en la Comunitat Valenciana, como lengua vehicular en casa; y en el caso de los informantes chinos, un 34,3\% afirmaba que utilizaba alguna de las variedades diatópicas ( $\mathrm{vd}$ ) del chino (min, shanghainés, etc.) como única lengua habitual en la familia. 


\begin{tabular}{|l|l|l|l|l|l|l|l|l|}
\hline Informantes & \multicolumn{2}{|l|}{ Sexo } & \multicolumn{2}{l|}{$\begin{array}{l}\text { Procedencia } \\
\text { geográfica }\end{array}$} & \multicolumn{2}{l|}{ Lengua habitual } \\
\hline chinos & $\begin{array}{l}22,86 \% \\
\mathrm{~h}\end{array}$ & $\begin{array}{l}74,29 \% \\
\mathrm{~m}\end{array}$ & $\begin{array}{l}68,57 \% \\
\text { este } \\
\text { sureste }\end{array}$ & $\begin{array}{l}17,14 \% \\
\text { norte }\end{array}$ & $\begin{array}{l}2,86 \% \\
\text { centro }\end{array}$ & $\begin{array}{l}34,28 \% \\
\mathrm{ch}\end{array}$ & $\begin{array}{l}31,43 \% \\
\text { ch y vd }\end{array}$ & $\begin{array}{l}34,28 \% \\
\text { vd }\end{array}$ \\
\hline españoles & $11,43 \%$ & $\begin{array}{l}88,57 \% \\
\mathrm{~m}\end{array}$ & $\begin{array}{l}97,14 \% \\
\text { Valencia } \\
\text { (provincia) }\end{array}$ & $\begin{array}{l}\text { 2,86\% } \\
\text { Alicante } \\
\text { (provincia) }\end{array}$ & $31,43 \% \mathrm{E}$ & $\begin{array}{l}2,86 \% \\
\text { e y val }\end{array}$ & $65,71 \%$ Val \\
\hline
\end{tabular}

TABLA 2: DATOS SOCIOLINGÜÍSTICOS DE LOS INFORMANTES

Una vez obtenidos los cuestionarios, se valoraron las respuestas. Se valoró el uso que de atenuadores e intensificadores realizaron ambos grupos de informantes, no obstante, la interpretación de los datos quizá haga necesario referir otros aspectos de la investigación no incluidos en este trabajo, como por ejemplo, el tipo de estrategia utilizada para realizar la petición ${ }^{17}$.

Los recursos que cada lengua vehicule para realizar la función de la atenuación o la intensificación son específicos y propios, y están condicionados, además, por las características tipológicas de la propia lengua. En este sentido, y dadas las diferencias morfosintácticas entre las lenguas estudiadas (chino-español), no fue posible comparar la presencia o ausencia de los mismos recursos lingüísticos. Por ejemplo, Lee-Wong (1998) y Zhang (1995a) consideran como atenuador léxico la presencia de partículas 语气词 (yuqi $c i$, modales ${ }^{18}$ ) como 吧 (ba), 呢 (ne) o 啊 (a/ya), que son propias del chino pero no del español. Un gran número de autores reconoce en dichas partículas un valor pragmático atenuador y cortés (Zhang, 1995a: 53 ${ }^{19}$; Lee-Wong, 1998: 401 ${ }^{20}$; Li y Thompson, 1989), si bien ello no implica que su caracterización semántica o su uso sean idénticos - o que, por concomitancia y en determinados contextos, no puedan adquirir otras connotaciones o significados-.

Por el contrario, en la lengua china los sustantivos y verbos presentan escasas posibilidades de flexión morfológica; en consecuencia, no pudo ser evaluado, desde el punto de vista de la atenuación o de la intensificación, el uso de la modificación morfológica interna mediante sufijos - aspecto que sí se considera cuando se describen ambos fenómenos en español (Briz, 1998; Siebold, 2008; Albeda, 2007; Albelda y Cestero, 2011; Cestero y Albelda, 2012) - . Además, la obtención de la muestra mediante un cuestionario escrito no permitió valorar la presencia de mecanismos de índole paralingüística, como la entonación, la risa, la gestualidad, etc.

\footnotetext{
${ }^{17}$ En este trabajo el término estrategia indica el tipo de estructura lingüística utilizada en el acto nuclear de la petición, y que habitualmente se clasifica según su nivel de oblicuidad. En Querol (2016) se tratan específicamente las diferencias y semejanzas en lo que respecta a las estrategias utilizadas por ambos grupos de informantes en la realización de peticiones. ${ }^{18}$ No hay un único término para denominar estas partículas, por lo que es frecuente su referencia en la bibliografía como mood words, senteces particles o modal particles.

${ }^{19}$ "They serve grammatical as well as pragmatic functions. In terms of the latter, they give utterances a soft touch, indicating tentativeness and possibility of negotiation.» (Zhang, 1995a: 53)

${ }^{20}$ «reducing the illocutionary force of direct request and increasing the politeness aspect» (Lee-Wong, 1998: 401)
} 


\section{normas}

Atenuadores e intensificadores en las peticiones de chinos y españoles | María Querol

Dicho esto, los recursos atenuadores valorados en este trabajo son los siguientes:

1. Modificación morfológica interna: sufijos (solo para el español)

2. Cuantificadores minimizadores

3. Selección léxica

4. Dilución de la responsabilidad de lo dicho mediante impersonalizaciones, apelación al juicio de la mayoría, recurrencia a presión o causa externa que motiva lo dicho, acotación de la opinión a la propia persona, etc.

5. Modificación temporal del verbo ${ }^{21}$ (solo para el español)

6. Aserción en forma de duda o probabilidad

7. Expresión de disculpa

8. Expresión de agradecimiento

9. Atenuación de la fuerza ilocutiva mediante partículas modales (solo para el chino)

10. Fórmulas de cortesía para realizar peticiones

11. Expresión de fórmulas fácticas de petición de consentimiento

12. Utilización de oraciones interrogativas

13. Modificación del acto de habla que restringe lo dicho mediante construcciones sintácticas condicionales

14. Negación de la condición preparatoria

15. Reduplicación (solo para el chino) 22

16. Utilización fórmulas de tratamiento de respeto

Como ya se ha anotado, en algunas investigaciones solo se valora el uso de atenuadores si estos aparecen en el núcleo de la petición. Sin embargo, algunos de los recursos típicamente atenuadores, como las expresiones de agradecimiento, las fórmulas fácticas de petición de consentimiento, la negación de la condición o la dilución de la responsabilidad, pueden no aparecer en el núcleo de la petición, pero sí formarían parte de la estructura de la petición, al incluirse, por ejemplo, explícitamente en el acto de apoyo (1) (2).

（1）老师，我们最近事情很多，那篇作文可不可以小? 一点？ (III, 2) 23 ('profesor, últimamente tenemos mucho trabajo, el texto ¿podría reducirse un poco?')

（2）老师，您布置的做业篇幅对我们来说有难度。能缩短些么？(III，25) ('profesor, la tarea que ha propuesto nos parece es un poco difícil, ¿podría reducirse un poco?')

\footnotetext{
${ }^{21}$ Se ha considerado, dada su aparición en el corpus, el uso del tiempo condicional, pretérito imperfecto de indicativo y pretérito imperfecto de subjuntivo.

${ }^{22}$ La reduplicación es un fenómeno morfológico característico, aunque no exclusivo, de la lengua china que presenta la siguiente forma: "a morpheme is repeated so that the original morpheme together with its repetition form a new Word» (Li y Thompson, 1989: 28). Aunque varias son las categorías susceptibles de reduplicarse - verbos, adjetivos, clasificadores, términos de parentesco... - la funcionalidad y significado resultante en todas ellas no es la misma. En el caso de la reduplicación del verbo suele indicar "menor intensidad de la acción", hecho que al formular propuestas o peticiones tiene un afecto atenuador. «En el primer caso, la duplicación expresa la modestia del que se ofrece a realizar la acción, y en el segundo caso, modera el tono con que se propone» (Xu y Zhou, 1997: 106).

${ }^{23}$ En los ejemplos, los números romanos indican la situación y los números arábicos el informante.
} 


\section{normas}

Atenuadores e intensificadores en las peticiones de chinos y españoles | María Querol

Además, por su propia naturaleza, en las peticiones indirectas puede resultar difícil establecer límites precisos entre el núcleo de la petición y el resto de la estructura, y, en consecuencia, también la decisión de contabilizar, o no, los recursos atenuadores. Por todo ello, en este estudio se considera la presencia de los recursos atenuadores en el conjunto de la estructura interna de la petición, según aparece descrita en Escandell (2004: 187-188).

Con respecto a los intensificadores, ya se ha mencionado el trabajo de Albelda (2007), que proporciona una exhaustiva lista de recursos, clasificados por niveles lingüísticos y categorías, susceptibles de vehicular la función intensificadora. La dificultad para aplicar dicha nómina en esta investigación reside en el hecho de que su diferenciación no resulta fácilmente aplicable a lenguas tipológicamente distintas a las occidentales. Es más, una crítica reiterada en relación al estudio de la lengua china es el intento de describirla utilizando categorías y parámetros propios de las lenguas occidentales (Rovira, 2010:135 $)^{24}$.

Por todo ello, la nómina de recursos considerados en el análisis de los corpus que forman parte de este trabajo nuevamente atiende, por una parte, a la idiosincrasia de las lenguas objeto de estudio y, por otra parte, a las realizaciones concretas que utilizaron los informantes que participaron en esta investigación. Así pues, estos son los intensificadores considerados y valorados en este trabajo:

1. cuantificación en grado superior de la cantidad o la cualidad mediante la modificación morfológica interna (sufijos, prefijos)

2. cuantificación en grado superior de la cualidad o la calidad mediante modificadores de carácter adjetival y/o adverbial

3. cuantificación en grado superior de la cantidad o la calidad mediante la selección léxica

4. cuantificación en grado superior de la cantidad o la cualidad mediante el uso de perífrasis, locuciones, interjecciones o colocaciones

5. expresión de certeza respecto a la dicho

Al igual que para los atenuadores, la presencia de estos recursos no solo se observó en el núcleo o estrategia de la petición, sino en el conjunto de su estructura interna. Asimismo, en ambos casos también se constata fácilmente que, de la nómina propuesta, algunos recursos afectan al enunciado y otros a la enunciación, tal y como Briz (1998) señalara. No obstante, no se ha mantenido dicha diferenciación, que Briz (1998) identifica con la diferencia entre semántica y pragmática, al entender que el uso de todos ellos tiene una finalidad pragmática como estrategia de cortesía, persuasiva, colaborativa...

\footnotetext{
${ }^{24}$ «la aplicación de modelos ajenos e inadecuados para la lengua china ha provocado situaciones paradójicas como, por ejemplo, gramáticas descriptivas del chino que no han incluido determinadas categorías sintácticas porque éstas no existían en las lenguas europeas -o su presencia en ellas es muy marginal.» (Rovira, 2010: 135)
} 


\section{normas}

Atenuadores e intensificadores en las peticiones de chinos y españoles | María Querol

Finalmente, cabe señalar que la representatividad de los recursos examinados se ha calculado con respecto al número global de respuestas aceptadas ${ }^{25}$. De esta manera, se pretende obtener el porcentaje de realizaciones en las que los hablantes chinos y españoles han mitigado e intensificado la fuerza ilocutiva de sus peticiones.

\section{ANÁLISIS DE LOS DATOS}

\subsection{Atenuación}

Con respecto a los datos obtenidos en el corpus chino, se pueden destacar varios aspectos: en primer lugar, la frecuencia de uso; y en segundo lugar, la probabilidad de atenuación en determinadas situaciones. Según se observa en la tabla 3, los valores obtenidos evidencian la tendencia hacia la utilización de 2 recursos atenuadores en cada petición. Además, la situación 11 es la que muestra un menor uso de este recurso y, por el contrario, las situaciones 2 y 7 son las que mayor uso evidencian.

\begin{tabular}{|c|c|c|c|c|c|c|c|c|c|c|c|c|c|c|c|}
\hline & $2^{26}$ & 3 & 4 & 6 & 7 & 8 & 9 & 10 & 11 & 12 & 13 & 14 & 15 & 16 & $\mathrm{Me}$ \\
\hline & $\mathrm{MIN}$ & LEX & $Y_{Y}^{D \| L}$ & $\begin{array}{l}\text { DU } \\
\text { DA }\end{array}$ & $c^{\text {DIS }}$ & $\begin{array}{l}\text { AGR } \\
A D\end{array}$ & $\begin{array}{l}\text { PA } \\
\text { RT }\end{array}$ & $\begin{array}{l}\text { COR } \\
T_{T}\end{array}$ & $\begin{array}{l}\text { CO } \\
\text { NS }\end{array}$ & INT & $\begin{array}{c}\mathrm{CO} \\
\mathrm{ND}\end{array}$ & $G^{N E}$ & $\begin{array}{l}{ }^{R E} \\
D\end{array}$ & RES & $\begin{array}{l}\text { me } \\
\text { dia }\end{array}$ \\
\hline $\mathrm{s.1}$ & $\begin{array}{l}71,8 \\
7 \% \\
\end{array}$ & $\begin{array}{l}12,5 \\
\% \\
\end{array}$ & 0 & 0 & 0 & $\begin{array}{l}15,6 \\
25 \% \\
\end{array}$ & $25 \%$ & $\begin{array}{l}3,12 \\
5 \%\end{array}$ & $\begin{array}{l}3,12 \\
5 \%\end{array}$ & 0 & $\begin{array}{l}3,12 \\
5 \%\end{array}$ & 0 & 0 & 0 & $\begin{array}{l}1,3 \\
4\end{array}$ \\
\hline s.2 & $\begin{array}{l}39,2 \\
8 \%\end{array}$ & $\begin{array}{l}3,57 \\
\%\end{array}$ & $75 \%$ & $\begin{array}{l}32,1 \\
\% 4\end{array}$ & $\begin{array}{l}14,2 \\
8 \%\end{array}$ & $\begin{array}{l}3,57 \\
\%\end{array}$ & $\begin{array}{l}39,2 \\
8 \%\end{array}$ & $\begin{array}{l}3,5 \% \\
7\end{array}$ & $50 \%$ & 0 & 0 & 0 & $\begin{array}{l}3,5 \\
7 \%\end{array}$ & 0 & $\begin{array}{l}2,6 \\
4\end{array}$ \\
\hline s.7 & $75 \%$ & $\begin{array}{l}43,7 \\
5 \%\end{array}$ & $\begin{array}{l}37,5 \\
\%\end{array}$ & 0 & $\begin{array}{l}3,12 \\
5 \%\end{array}$ & $\begin{array}{l}12,5 \\
\%\end{array}$ & $\begin{array}{l}37,5 \\
\%\end{array}$ & $\begin{array}{l}15,6 \\
25 \%\end{array}$ & $\begin{array}{l}9,37 \\
5 \%\end{array}$ & 0 & $\begin{array}{l}6,25 \\
\%\end{array}$ & 0 & 0 & 0 & $\begin{array}{l}2,4 \\
1\end{array}$ \\
\hline s.8 & $90 \%$ & $\begin{array}{l}3,33 \\
\%\end{array}$ & 0 & 0 & 0 & $\begin{array}{l}16,6 \\
7\end{array}$ & $10 \%$ & $\begin{array}{l}6,67 \\
\%\end{array}$ & $\begin{array}{l}13,3 \\
3 \%\end{array}$ & 0 & 0 & 0 & $\begin{array}{l}3,3 \\
3 \%\end{array}$ & 0 & $\begin{array}{l}1,4 \\
3\end{array}$ \\
\hline s.5 & $\begin{array}{l}56,6 \\
7 \%\end{array}$ & $\begin{array}{l}16,6 \\
7 \%\end{array}$ & 0 & 0 & $\begin{array}{l}6,67 \\
\%\end{array}$ & 0 & $\begin{array}{l}3,33 \\
\%\end{array}$ & $20 \%$ & $\begin{array}{l}16,6 \\
7 \%\end{array}$ & $\begin{array}{l}30 \\
\%\end{array}$ & $\begin{array}{l}23,3 \\
3 \%\end{array}$ & $\begin{array}{l}6,66 \\
7 \%\end{array}$ & $\begin{array}{l}3,3 \\
3\end{array}$ & 0 & $\begin{array}{l}1,8 \\
3\end{array}$ \\
\hline s.10 & $\begin{array}{l}6,25 \\
\%\end{array}$ & $\begin{array}{l}31,2 \\
5 \%\end{array}$ & $\begin{array}{l}3,12 \\
5 \%\end{array}$ & $\begin{array}{l}3,12 \\
5 \%\end{array}$ & 0 & $\begin{array}{l}37,5 \\
\%\end{array}$ & $\begin{array}{l}3,12 \\
5 \%\end{array}$ & $\begin{array}{l}65,6 \\
25 \%\end{array}$ & $\begin{array}{l}18,7 \\
5 \%\end{array}$ & 0 & 0 & 0 & $\begin{array}{l}3,1 \\
25\end{array}$ & $\begin{array}{l}43,7 \\
5 \%\end{array}$ & $\begin{array}{l}2,1 \\
6\end{array}$ \\
\hline s.3 & $\begin{array}{l}103, \\
22 \%\end{array}$ & 0 & $\begin{array}{l}32,2 \\
5 \%\end{array}$ & $\begin{array}{l}6,45 \\
\%\end{array}$ & 0 & $\begin{array}{l}3,22 \\
\%\end{array}$ & $\begin{array}{l}25,8 \\
1 \%\end{array}$ & $\begin{array}{l}16,1 \\
3 \%\end{array}$ & $\begin{array}{l}3,22 \\
\%\end{array}$ & $\begin{array}{l}3,2 \\
2 \%\end{array}$ & 0 & 0 & 0 & $\begin{array}{l}16,1 \\
3 \%\end{array}$ & 2,1 \\
\hline s.11 & $\begin{array}{l}69,7 \\
\%\end{array}$ & 0 & $\begin{array}{l}6,06 \\
\%\end{array}$ & 0 & 0 & $\begin{array}{l}3,03 \\
\%\end{array}$ & $\begin{array}{l}15,1 \\
5 \%\end{array}$ & $\begin{array}{l}18,1 \\
8 \%\end{array}$ & $\begin{array}{l}12,1 \\
2 \%\end{array}$ & 0 & 0 & 0 & 0 & $\begin{array}{l}9,09 \\
\%\end{array}$ & $\begin{array}{l}1,3 \\
3\end{array}$ \\
\hline $\mathrm{T}$ & $\begin{array}{l}64,1 \\
\% \\
\end{array}$ & $\begin{array}{l}14,1 \\
1 \%\end{array}$ & $\begin{array}{l}18,5 \\
5 \%\end{array}$ & $\begin{array}{l}4,84 \\
\%\end{array}$ & $\begin{array}{l}2,82 \\
\%\end{array}$ & $\begin{array}{l}11,6 \\
\%\end{array}$ & $\begin{array}{l}19,7 \\
6 \%\end{array}$ & $\begin{array}{l}18,9 \\
5 \%\end{array}$ & $\begin{array}{l}15,3 \\
2 \% \\
\end{array}$ & $\begin{array}{l}4,0 \\
3 \%\end{array}$ & $\begin{array}{l}4,03 \\
\%\end{array}$ & $\begin{array}{l}0,81 \\
\% \\
\end{array}$ & $\begin{array}{l}1,6 \\
1 \%\end{array}$ & $\begin{array}{l}8,87 \\
\%\end{array}$ & $\begin{array}{l}1,8 \\
9 \\
\end{array}$ \\
\hline
\end{tabular}

TABLA 3: ATENUADORES EN EL CORPUS CHINO

Por otra parte, los resultados obtenidos parecen mostrar que la distancia social y el poder social no son las únicas variables con incidencia en la realización, o no, de estos recursos, pues otros factores como, por ejemplo, el nivel de oblicuidad de la estrategia utilizada en la petición, podrían tener también un papel muy relevante. Así, en la situación 2 los hablantes prefirieron de forma mayoritaria realizar la petición utilizando una estrategia directa, como es la expresión de deseo (71,43 \%) (Querol, 2016). Sin embargo, dicho nivel

\footnotetext{
${ }^{25}$ No todas las respuestas de todos los informantes pudieron ser valoradas. En la mayoría de ocasiones que esto ocurrió se debió a que los informantes no respondieron a la cuestión, o no lo hicieron pertinentemente, aunque en algún caso también la ilegibilidad de la caligrafía motivó la exclusión de alguna de las respuestas. El intervalo de respuestas aceptadas oscila entre 28 y 35, dependiendo de la situación. En una futura ampliación de este estudio sería pertinente valorar la introducción de un incentivo que motive a los informantes a contestar los cuestionarios, y hacerlo, además, adecuadamente.

${ }^{26}$ La numeración corresponde al recurso atenuador presentado en el apartado 2.
} 


\section{normas}

Atenuadores e intensificadores en las peticiones de chinos y españoles | María Querol

de oblicuidad se ve neutralizado por la utilización, también de forma mayoritaria, de dos recursos atenuantes: por una parte, la dilución de la responsabilidad que implica poner la petición en boca de un amigo; y por otra parte, la adición, junto a la expresión de deseo, de una fórmula fática de petición de acuerdo.

(3) 我有一个同学要来我们这住两个星期, 你们不介意吧 ${ }^{27}$ ? (II, 4) ('tengo un compañero que quiere venir aquí dos semanas, ¿no estáis de acuerdo?')

(4) 我有一个朋友要来住两天, 可以吗? (II, 7) ('tengo un amigo que quiere venir y estar dos días, ¿es posible?'28)

La segunda de las situaciones en la que se utilizó un mayor número de recursos atenuadores es la situación 7. En esta destaca el uso, en ocasiones simultáneo, de tres tipos de atenuadores. En primer lugar, la selección léxica, pues el hablante no demanda al otro interlocutor que limpie, sino que le ayude en la tarea (5); en segundo lugar, la dilución de la responsabilidad, pues el hablante mitiga el posible efecto negativo de la petición al involucrarse él también en la tarea y decir que lo harán juntos (6); y en tercer lugar, el uso de cuantificadores minimizadores (6). En chino existen los llamados 结果补语 (jieguo buyu, 'complementos resultativos'), que se utilizan para denotar cómo es el resultado final de la acción. En el caso del verbo 打扫 (dasao, 'limpiar') se suele acompañar de la forma 干净 (ganjing, 'limpio'), si es que se espera que la acción acabe con este resultado. Parece lógico pensar que en la situación 7 el deseo del hablante sea conseguir este resultado, y por esta misma razón se debe valorar la elección de no expresarlo explícitamente y cuantificar de forma indefinida la acción verbal, 一下 (yi xia, 'un poco'), 一点 (yi dian, 'un poco').

(5) 我要去打扫会场地, 人手不太够, 你能来帮帮我忙吗? (VII, 6) ('quiero limpiar el piso, pero no hay demasiada gente, ¿podrías venir y echarme una mano?')

(6) 我们的房间太乱吧, 有别的事吗? 我们一起打扫一下吧 (VII, 8) ('tenemos el piso demasiado desastrado, ¿tienes algo que hacer? Podemos limpiarlo juntos un poco.')

Es más, el recurso atenuador más utilizado en el corpus chino, es, sin lugar a dudas, el cuantificador minimizador de la acción verbal (6) (7) - un uso que parece propio de los hablantes chinos, pues no se da en el corpus español. Le siguen, en frecuencia de uso, la utilización de partículas modales (6) (8) (9) (10) (13) y la estrategia de diluir la responsabilidad, fundamentalmente porque en la situación 2 la mayoría de los informantes optó por atribuir explícitamente al amigo, y no al propio hablante, el deseo de quedarse. No obstante, no es este el único recurso que los informantes chinos utilizaron para diluir la responsabilidad de la petición. Otras estrategias para conseguir dicho efecto son la propuesta de compartir la tarea (9) (10), que, como ya se ha mencionado, realizaron con bastante frecuencia los informantes en la situación 7, la expresión de juicios no asertivos

\footnotetext{
27 吧 (ba) pertenece al denominado grupo de las partículas modales 语气词 (yuqi cl), grupo en el que se incluyen también partículas como呢 (ne) o 啊 $(a / y a)$.

${ }^{28}$ Pese a lo indicado en el cuestionario, el informante optó por utilizar las formas朋友 (pengyou, 'amigo') y 两天 (liangtian, 'dos días').
} 


\section{normas}

Atenuadores e intensificadores en las peticiones de chinos y españoles | María Querol

en la justificación que acompaña la petición (11) (12) o la utilización del plural, inclusivo o no, para expresar el punto de vista (13) (14).

(7) 能借我一下你的笔记看一 眼? (VIII, 33) ('¿puedes dejarme un momento los apuntes que les eche un vistazo?')

(8) 陪哥去打扫场地吧 (VII, 33) ('hermano me acompañas y vamos a limpiar')

(9) 我们的房间太乱吧, 有别的事吗, 我们一起打扫一下吧 (VII, 8) ('nuestro piso está demasiado desastrado, ¿tienes alguna cosa que hacer? Podemos limpiarlo un poco juntos')

(10) 咋们一起打扫场地吧 (VII, 20) ('vamos juntos a limpiar')

(11) 老师最近作业量好像有点大，有时要写得很晚，有没有可能减小点？(III, 8) ('profesor, últimamente parece que hay mucha tarea, y entonces acabamos muy tarde, ¿podría reducirse un poco?')

(12) 老师,这次作业的篇幅似乎大了点, 能不能短点? (III, 18) ('profesor, parece que la tarea tiene una longitud un poco extensa, ¿podría reducirse?') (13) 老师同学们都觉得作业的篇幅稍何点长, 可不可以把字数要求减短小 呢? (III, 15) ('profesor, todos los estudiantes piensan que la tarea es un poco extensa, ¿se podría reducir un poco el número de caracteres exigido?')

(14) 老师, 我们这周别科目的作业很多，能不能把这篇作业篇幅减小一些 (II, 29) ('profesor, esta semana de las otras asignaturas tenemos mucha tarea, ¿se podría reducir un poco la longitud de la tarea?')

Aunque las estrategias léxicas atenuadoras no son el recurso más frecuente, resulta pertinente destacar su realización, pues en la mayoría de los casos se opta por una selección léxica que incrementa el sentido, no solo de pertenencia a la misma comunidad, sino de solidaridad (15). En este sentido, también Lee-Wong (1994: 499-500) había destacado el frecuente uso de 帮 (bang, 'ayudar') en las peticiones, que explicaba como una preferencia de los hablantes chinos por la autohumillación como estrategia de cortesía. No obstante, en el corpus también aparecen frecuentemente formas como 配合 (peihe, 'colaborar’) (16) o 帮忙 (bangmang, 'echar una mano') (17) con idéntico fin.

(15) 不好意思, 我想买带电视机， 但最近手头有点紧，你可以帮我一下? (I, 20) ('disculpa, me gustaría comprar una televisión, pero ahora voy un poco justo de dinero, ¿podrías ayudarme un poco?')

(16) 请你 配合一下, 将 车换地方停 (X, 1) ('por favor, colabora un poco, cambia el coche y apárcalo en otro lugar')

(17) 我要去打扫会场地，人手不太够，你能来帮帮我忙吗? (VII， 6) ('quiero limpiar el piso, pero no hay demasiada gente, ¿podrías venir y echarme una mano?')

Se ha incluido también en el grupo de selección léxica los casos en los que el hablante decidía omitir alguna palabra o expresión que directamente aludiera a la petición o a su contenido. Este hecho se ha dado especialmente en la situación 1, en la que, en ocasiones, los informantes pedían ayuda o dinero pero omitían el fin (comprar una televisión). 
(18) 朋友我最近手头比较紧, 你能借钱我钱吗? (I, 12) ('amigo últimamente voy algo justo de dinero, ¿podrías prestarme?')

(19) 哥小弟想买一台电视机, 现在还缺点钱, 你懂的。(I, 19) ('hermano desearía comprarme una televisión pero ahora voy algo justo de dinero, ¿me entiendes?')

Comparativamente, la nómina de recursos atenuadores en el corpus español es sensiblemente menor a la de sus homólogos chinos. En el conjunto de la situaciones la media de uso de atenuadores chinos resulta ser casi el doble que en el corpus español $(1,98$ /vs./ 1,08); pese a ello, en la mayor parte de realizaciones y situaciones los informantes españoles sí que utilizaron algún elemento atenuador.

\begin{tabular}{|c|c|c|c|c|c|c|c|c|c|c|c|c|c|c|c|}
\hline & $1^{29}$ & 2 & 3 & 4 & 5 & 6 & 7 & 8 & 10 & 11 & 12 & 13 & 14 & 16 & $\mathrm{Me}$ \\
\hline & SUF & $\mathrm{MIN}$ & LEX & DILY & VER & $\begin{array}{l}\text { AGR } \\
A D\end{array}$ & $\begin{array}{l}\text { DIS } \\
C\end{array}$ & $\begin{array}{l}\text { AGR } \\
A D\end{array}$ & $\begin{array}{l}\text { CO } \\
\text { RT }\end{array}$ & $\begin{array}{l}\text { CO } \\
\text { NS }\end{array}$ & INT & $\begin{array}{l}\text { CON } \\
\text { D }\end{array}$ & $\begin{array}{c}\mathrm{NE} \\
\mathrm{GX}\end{array}$ & RES & $\begin{array}{l}\text { me } \\
\text { dia }\end{array}$ \\
\hline s.1 & 0 & 0 & 0 & 0 & $60 \%$ & 0 & 0 & 0 & $\begin{array}{l}8,57 \\
\% \\
\end{array}$ & $\begin{array}{l}2,86 \\
\% \\
\end{array}$ & $\begin{array}{l}2,8 \\
6 \% \\
\end{array}$ & $\begin{array}{l}5,71 \\
\% \\
\end{array}$ & 0 & 0 & 0,8 \\
\hline s.2 & $\begin{array}{l}6,4 \\
5 \% \\
\end{array}$ & $\begin{array}{l}6,45 \\
\%\end{array}$ & $\begin{array}{l}3,22 \\
\%\end{array}$ & $\begin{array}{l}6,45 \\
\%\end{array}$ & $\begin{array}{l}32,2 \\
6 \% \\
\end{array}$ & $\begin{array}{l}, 45 \\
\% \\
\end{array}$ & 0 & 0 & 0 & $\begin{array}{l}, 45 \\
\% \\
\end{array}$ & 0 & $\begin{array}{l}6,45 \\
\% \\
\end{array}$ & $\begin{array}{l}3,22 \\
\% \\
\end{array}$ & 0 & $\begin{array}{l}0,7 \\
7 \\
\end{array}$ \\
\hline s.5 & 0 & 0 & 0 & $\begin{array}{l}2,94 \\
\%\end{array}$ & $\begin{array}{l}52,9 \\
4 \% \\
\end{array}$ & 0 & $\begin{array}{l}2,9 \\
4 \% \\
\end{array}$ & $\begin{array}{l}5,88 \\
\%\end{array}$ & $\begin{array}{l}11,7 \\
6 \%\end{array}$ & $\begin{array}{l}, 88 \\
\% \\
\end{array}$ & $\begin{array}{l}8,8 \\
2 \% \\
\end{array}$ & $\begin{array}{l}23,5 \\
3 \% \\
\end{array}$ & 0 & $\begin{array}{l}35,2 \\
9 \%\end{array}$ & 1,5 \\
\hline s.7 & 0 & $\begin{array}{l}8,82 \\
\%\end{array}$ & $\begin{array}{l}2,94 \\
\%\end{array}$ & $\begin{array}{l}8,82 \\
\%\end{array}$ & $\begin{array}{l}17,6 \\
5 \%\end{array}$ & 0 & 0 & $\begin{array}{l}5,88 \\
\%\end{array}$ & $\begin{array}{l}8,82 \\
\%\end{array}$ & $\begin{array}{l}14,7 \\
1 \%\end{array}$ & 0 & $\begin{array}{l}14,7 \\
1 \%\end{array}$ & 0 & 0 & $\begin{array}{l}0,8 \\
2\end{array}$ \\
\hline s.8 & 0 & 0 & $\begin{array}{l}5,71 \\
\%\end{array}$ & 0 & $\begin{array}{l}48,5 \\
7 \%\end{array}$ & 0 & 0 & $\begin{array}{l}11,43 \\
\%\end{array}$ & $\begin{array}{l}25,7 \\
1 \%\end{array}$ & 0 & 0 & $\begin{array}{l}8,57 \\
\%\end{array}$ & 0 & 0 & 1 \\
\hline $\begin{array}{l}\mathrm{s.1} \\
0\end{array}$ & 0 & 0 & $\begin{array}{l}5,71 \\
\%\end{array}$ & 0 & $\begin{array}{l}22,8 \\
6 \%\end{array}$ & 0 & 0 & $\begin{array}{l}2,86 \\
\%\end{array}$ & $\begin{array}{l}2,86 \\
\%\end{array}$ & 0 & 0 & $\begin{array}{l}2,86 \\
\%\end{array}$ & 0 & $\begin{array}{l}82,8 \\
6 \%\end{array}$ & 1,2 \\
\hline S.3 & 0 & $\begin{array}{l}3,12 \\
5 \% \\
\end{array}$ & $\begin{array}{l}3,12 \\
5 \% \\
\end{array}$ & $\begin{array}{l}18,7 \\
5 \%\end{array}$ & $50 \%$ & 0 & 0 & $\begin{array}{l}3,125 \\
\%\end{array}$ & $\begin{array}{l}12,5 \\
\%\end{array}$ & 0 & 0 & $\begin{array}{l}3,12 \\
5 \% \\
\end{array}$ & $\begin{array}{l}9,37 \\
5 \% \\
\end{array}$ & $25 \%$ & $\begin{array}{l}1,2 \\
8 \\
\end{array}$ \\
\hline $\begin{array}{l}\text { S. } 1 \\
1 \\
\end{array}$ & 0 & 0 & 0 & $\begin{array}{l}11,7 \\
6 \%\end{array}$ & $\begin{array}{l}61,7 \\
6 \%\end{array}$ & 0 & 0 & 0 & $\begin{array}{l}9,37 \\
5 \%\end{array}$ & 0 & 0 & $\begin{array}{l}3,03 \\
\%\end{array}$ & 0 & $\begin{array}{l}42,4 \\
2 \%\end{array}$ & $\begin{array}{l}1,2 \\
6\end{array}$ \\
\hline$T$ & $\begin{array}{l}0,7 \\
4 \% \\
\end{array}$ & $\begin{array}{l}17,1 \\
4 \% \\
\end{array}$ & $\begin{array}{l}2,59 \\
\%\end{array}$ & $\begin{array}{l}5,92 \\
5 \% \\
\end{array}$ & $\begin{array}{l}43,3 \\
3 \% \\
\end{array}$ & $\begin{array}{l}0,74 \\
\% \\
\end{array}$ & $\begin{array}{l}0,3 \\
7 \% \\
\end{array}$ & $3,7 \%$ & $10 \%$ & $3,7 \%$ & $\begin{array}{l}1,4 \\
8 \% \\
\end{array}$ & $\begin{array}{l}8,52 \\
\% \\
\end{array}$ & $\begin{array}{l}1,48 \\
\% \\
\end{array}$ & $\begin{array}{l}23,3 \\
3 \% \\
\end{array}$ & $\begin{array}{l}1,0 \\
8 \\
\end{array}$ \\
\hline
\end{tabular}

TABLA 4: ATENUADORES EN EL CORPUS ESPAÑOL

Además de la diferencia con respecto al número de recursos atenuadores utilizados en cada petición, llama la atención que españoles y chinos apenas coincidan en las situaciones con mayor y menor frecuencia de uso de estrategias atenuadoras, y que incluso en algunas de ellas, como por ejemplo la 2 y la 11, tengan comportamientos totalmente opuestos.

Los informantes españoles atenuaron con mayor frecuencia las situaciones 5, 3 y 11 . En los tres casos se trata de situaciones en las que existe una relación de asimetría entre los interlocutores, si bien el número y tipo de atenuadores utilizados (modificación temporal del verbo y utilización de formas de tratamiento de respeto) lo que muestra, dada la metodología utilizada en este estudio, es que los informantes son conocedores de las normas de cortesía, en el sentido tradicional del término, en español, aunque a veces no sean muy coherentes en su utilización. Así ocurre en el ejemplo (22), en el que el informante

\footnotetext{
${ }^{29}$ La numeración corresponde al recurso atenuador presentado en el apartado 2.
} 


\section{normas}

Atenuadores e intensificadores en las peticiones de chinos y españoles | María Querol

utiliza el tratamiento de respecto "usted" para dirigirse al profesor en el acto de apoyo, pero en la petición lo tutea ${ }^{30}$.

(20) Camarero, por favor, ¿podría cambiar mi pedido? ( $\mathrm{V}, 19)$

(21) Perdone, ¿podría ampliarnos el plazo de entrega del trabajo $(X I, 10)$

(22) Creo que el trabajo que nos ha mandado es demasiado largo, ¿no podrías

considerar la posibilidad de dejar que lo hagamos un poco más corto? (III, 14)

En las situaciones 3 y 11, además, los informantes utilizaron estrategias con un bajo nivel de oblicuidad (indirectas convencionalizadas) prácticamente siempre para realizar las peticiones (Querol, 2016). Esta acumulación de recursos parece mostrar que los informantes españoles consideraron estas dos situaciones especialmente amenazadoras.

Las situaciones 2, 1 y 7 , en cambio, son en las que menor número de recursos atenuadores se registraron - datos que difieren notablemente de los de sus homólogos chinos - La cuestión que surge entonces es qué pudo motivar dicha diferencia: ¿la estrategia de petición utilizada? ¿la naturaleza de la petición? ¿diferencias socioculturales?... No parece que la estrategia utilizada en la petición explique dicho comportamiento, pues los informantes españoles utilizaron estrategias muy diferentes en cada una de las tres situaciones (Querol, 2016). En consecuencia, debieron de ser diferencias interpretativas, posiblemente por cuestiones socioculturales, las que motivaron actuaciones tan diversas. Por ejemplo, en el caso de la situación 7 parece evidente que los informantes españoles la interpretaron de diferente forma a sus homólogos chinos. Los informantes españoles debieron de considerar la situación más que como una petición, como un acto de reproche, al entender que el compañero de piso no había cumplido con las normas establecidas y pactadas (el que hace una fiesta luego debe limpiar) - de ahí que no solo utilizaran un número reducido de atenuadores, sino también estrategias directas para realizar la petición-.

(23) Oye, cuando termines la fiesta limpia todo el piso porque yo no tengo porqué limpiar lo que ensuciéis. (VII, 31)

(24) Oye, creo que después de la fiesta que hiciste anoche deberías limpiar un poco y no tener que hacerlo yo siempre, ¿no crees? (VII, 24)

El corpus español también muestra, en términos generales, la preferencia de los informantes españoles por uno de los recursos atenuadores, en concreto, la modificación morfológica del verbo mediante el tiempo (condicional o pretérito imperfecto) - recurso que no puede ser comparado con sus homólogos chinos porque no se da en su lengua- Cuantitativamente, los siguientes recursos, según su recurrencia, serían la utilización de fórmulas de tratamiento de respeto, la expresión de cortesía y las modificaciones del acto de habla que restringen lo dicho mediante construcciones sintácticas oracionales. Como se ha mencionado anteriormente, el elevado uso que en el corpus se observa de las

\footnotetext{
${ }^{30}$ Pese a que la gramática del español prescribe también el uso del tratamiento de respeto mediante, por ejemplo, el pronombre usted en situaciones formales y/o de reverencia y respeto, la realidad es que dichas fórmulas están claramente en desuso, al menos entre las generaciones más jóvenes y en las clases medias-altas (Blas, 1994).
} 


\section{normas}

Atenuadores e intensificadores en las peticiones de chinos y españoles | María Querol

fórmulas de tratamiento de respeto en las situaciones de asimetría social indica, más que su uso real, la conciencia lingüística (o pragmática) de los informantes españoles.

\subsection{Intensificación}

Aunque semánticamente contrarios, en el uso de atenuadores e intensificadores en las peticiones se identifica un mismo fin persuasivo y, en algunos casos, también una estrecha vinculación con el fenómeno de la cortesía (Briz, 1998; Albelda, 2005). No obstante, su uso, tanto en el corpus chino como en el corpus español, es significativamente menor al de los recursos atenuadores, probablemente por el tipo de acto de habla examinado.

\begin{tabular}{|l|l|l|l|l|l|l|}
\hline $\mathrm{S} / \mathrm{I}$ & $2^{31}$ & 3 & 4 & 5 & $\mathrm{~T}$ & $\mathrm{ME}$ \\
\hline & ADJ/ADV & LEX & LOC & CERT & total & media \\
\hline 1 & $21,875 \%$ & 0 & 0 & $6,25 \%$ & $3,63 \%$ & 0,28 \\
\hline 2 & $25 \%$ & 0 & 0 & $3,57 \%$ & $3,22 \%$ & 0,28 \\
\hline 7 & $6,25 \%$ & 0 & 0 & $3,125 \%$ & $1,2 \%$ & 0,09 \\
\hline 8 & $10 \%$ & 0 & 0 & $0 \%$ & $1,2 \%$ & 0,1 \\
\hline 5 & $50 \%$ & 0 & 0 & $0 \%$ & $6,04 \%$ & 0,5 \\
\hline 10 & $50 \%$ & 0 & 0 & $0 \%$ & $6,45 \%$ & 0,5 \\
\hline 3 & $35,48 \%$ & 0 & 0 & $3,22 \%$ & $4,84 \%$ & 0,39 \\
\hline 11 & $9,09 \%$ & 0 & 0 & $0 \%$ & $1,21 \%$ & 0,09 \\
\hline total & $25,81 \%$ & 0 & 0 & $2,016 \%$ & $27,82 \%$ & 0,28 \\
\hline
\end{tabular}

TABLA 5: INTENSIFICADORES EN EL CORPUS CHINO

Con respecto a los datos obtenidos en el corpus chino, los intensificadores se utilizaron con mayor frecuencia, por este orden, en las situaciones 10, 5 y 3.

En la situación 3 los intensificadores aparecen en el acto de apoyo que se utiliza como excusa o justificación de la petición, y en el que determinadas formas adverbiales y adjetivas incrementan la bastedad o dificultad de la tarea (25) (26). Al justificar la necesidad de solicitar una ampliación en el plazo para su entrega o una reducción de sus límites, el hablante "aumenta el impacto de la petición".

(25) 老师，作业太长，真写不了，短点儿吧？(III, 3) ('profesor, el deber es demasiado, no lo acabaremos, ¿y si se reduce un poco?')

(26) 老师, 你的作业太多了, 可以减点吗? (III, 4) ('profesor, mi deber es demasiado, ¿se podría reducir un poco?')

En la situación 2 (27) (28), y en algunos casos también en la situación 1 (29), el uso de los intensificadores pretende mostrar la existencia de una estrechísima relación entre el hablante y el amigo que desea ir (o al que se le pide el dinero), y con ello, probablemente,

\footnotetext{
${ }^{31}$ La numeración corresponde al recurso intensificador presentado en el apartado 2.
} 


\section{normas}

Atenuadores e intensificadores en las peticiones de chinos y españoles | María Querol

se intenta incrementar la acción persuasiva del hablante al solicitar al resto de compañeros de piso que aquel pueda quedarse dos semanas.

(27) 我一兄弟要来住一会啊, 你们没意见吧? (II, 18) ('un amigo, que es como un hermano, va a venir a quedarse unos días, ¿os importa?')

(28) 我有一个好朋友要过来住在两个星期, 麻烦大家了? (II, 28) ('tengo un buen amigo que quiere venir a quedarse dos semanas, ¿os importa?')

(29)最近想买一台电视机, 兄弟你能借我点钱不? ( I, 10) ('me gustaría comprarme una tele, ¿hermano podrías dejarme algo de dinero?')

Finalmente, en los ejemplos (30-33) se presenta el uso que los informantes realizaron de la forma adverbial 刚 (gang, 'acabar de') en las situaciones 5 y 10, pues su utilización en el corpus muestra algunas diferencias con respecto a los casos más prototípicos incluidos en la categoría de intensificadores. En la situación 5 el uso de esta forma subraya y enfatiza el lapso de tiempo tan escaso que ha transcurrido desde que el hablante realizó la comanda hasta que ha decidido cambiar de opinión (30) (31). No necesariamente tiene que ser cierta la inmediatez de dichas acciones; $y$, aunque así fuera, al explicitarlo parece que se subraya que, dado que el plato no estará hecho, no debería de causar demasiadas molestias la petición que se realiza - cambiar la comanda-. En los ejemplos (32) y (33), que corresponden a la situación 10, el uso de la forma 刚 (gang, 'acabar de') subraya que el incendio acaba de suceder. Nuevamente, no necesariamente debe ser cierto el enunciado, si bien el uso intencional de la mencionada forma incrementa la sensación de peligro. En ambos casos se ha considerado que, de alguna manera, el uso de esta forma "aumenta el impacto de la petición", de ahí que sus manifestaciones hayan sido incluidas en la nómina de recursos intensificadores.

(32) 服务员, 不好意思, 刚刚点的那个菜可以改吗？改成xx菜？不好意思啊 $(V, 29)$ ('camarero, disculpe, el plato que acabo de pedir ¿podría cambiarlo? ¿cambiarlo por XXX? Disculpe las molestias')

(33) 不好意思, 我可以更改一下我刚点的菜吗? ( $V, 23)$ ('disculpe, ¿podría cambiar el plato que acabo de elegir?')

(32) 先生, 这房子刚发生火灾, 为了你的车的安全, 请您换了地方停车。(X, 6) ('señor, en el piso acaba de ocurrir un incendio, por su seguridad, por favor, ¿podría cambiar el coche y aparcarlo en otro sitio?')

(33) 这里刚着火, 请换个地方停车, 好吗? (X, 7) ('aquí dentro acaba de ocurrir un incendio, por favor, cambia el coche y aparca en otro lugar, ¿de acuerdo?') 


\begin{tabular}{|c|c|c|c|c|c|c|c|}
\hline $\mathrm{S} / \mathrm{l}$ & $1^{32}$ & 2 & 3 & 4 & 5 & $T$ & $\mathrm{Me}$ \\
\hline & Pref- suf & Adv/ adj & Lex & Loc & Cert & Total & media \\
\hline s. 1 & $2,86 \%$ & $17,14 \%$ & $5,71 \%$ & $34,28 \%$ & $8,57 \%$ & $8,89 \%$ & 0,68 \\
\hline s. 2 & $3,22 \%$ & $12,9 \%$ & $12,9 \%$ & 0 & $6,45 \%$ & $4,07 \%$ & 0,35 \\
\hline s. 7 & 0 & $2,94 \%$ & $14,7 \%$ & 8,82\% & $2,94 \%$ & $3,7 \%$ & 0,29 \\
\hline s. 8 & 0 & $2,94 \%$ & 0 & $5,88 \%$ & 0 & $1,11 \%$ & 0,09 \\
\hline s. 5 & 0 & 0 & 0 & $11,43 \%$ & 0 & $1,48 \%$ & 0,11 \\
\hline s. 10 & 0 & $17,14 \%$ & 0 & $17,14 \%$ & 0 & $4,44 \%$ & 0,34 \\
\hline s. 3 & $6,25 \%$ & $50 \%$ & $3,125 \%$ & 0 & 0 & $7,03 \%$ & 0,59 \\
\hline s. 11 & 0 & $20,59 \%$ & 0 & $2,94 \%$ & $2,94 \%$ & $3,33 \%$ & 0,26 \\
\hline $\mathrm{T}$ & $1,48 \%$ & $14,07 \%$ & $4,44 \%$ & $10,37 \%$ & $2,59 \%$ & $32,96 \%$ & 0,33 \\
\hline
\end{tabular}

TABLA 6: INTENSIFICADORES EN EL CORPUS ESPAÑOL

A diferencia de lo observado en el uso de los atenuadores, los informantes españoles utilizaron con más frecuencia que los informantes chinos las estrategias intensificadoras, y además con una mayor variedad de recursos. Si los informantes chinos utilizaron, fundamentalmente, recursos de carácter adjetivo o adverbial para intensificar sus enunciados, los hablantes españoles alternaban el uso de dichos recursos con el de perífrasis, locuciones y colocaciones. En cambio, la modificación morfológica interna mediante sufijos (34) y prefijos (35), aunque también posible para la lengua española, no tuvo demasiada recurrencia - solo en el 1,48\% del total de las respuestas aparecía este recurso- .

(34) Chicos, ¿os importaría que mi amigo se quedase dos semanas en nuestro piso? os lo agradecería muchísimo (II, 15)

(35) He visto una tele que está súper bien y por muy buen precio ¿me dejarías $100 €$ que me faltan para poder tenerla? $(I, 32)$

A diferencia de lo observado en el corpus chino, en el corpus español el uso de intensificadores destaca sobremanera en la situación 1. Pese a dicha diferencia cuantitativa, el fin es idéntico en ambos casos, subrayar que el dinero se devolverá con gran celeridad.

\footnotetext{
${ }^{32}$ La numeración corresponde al recurso intensificador presentado en el apartado 2.
} 


\section{normas}

Atenuadores e intensificadores en las peticiones de chinos y españoles | María Querol

(36) Hola quería hablar contigo. Mira necesito que me dejes $100 €$ para comprar una televisión para los dos, en cuanto pueda te los devuelvo $(I, 11)$

(37) Por favor, me puedes prestar $100 €$, los necesito urgentemente y te los devolveré en el menor plazo $(1,5)$

(38) 我需要一台电视机, 但是我的钱不太够, 你给以借我一点吗? 我 去尽 快还给你 (I, 23) ('necesito una televisión, pero no tengo demasiado dinero, ¿podrías prestarme algo? Rápidamente te lo devolveré')

(39) 那个...不好意思, 我想买一个电视机, 你啊能借我点钱? 我马上就还你

$(\mathrm{l}, 7)$ ('esto ... disculpa, me gustaría comprar una televisión, ¿podrías dejarme algo de dinero? Te lo devuelvo enseguida')

La situación 3 también muestra un elevado índice de uso de intensificadores, la mayoría de los cuales se utiliza para denotar una elevada carga de trabajo, y con ello justificar la petición de que este se reduzca.

(40) El trabajo es muy largo, tenemos muchísimas cosas que hacer, ¿puedes reducir la longitud del trabajo? (III, 22)

(41) ¿Cabría la posibilidad de cambiar la longitud del trabajo? Tenemos muchísimos y poco tiempo (III, 21)

La situación 10, que en el corpus chino había destacado por el elevado número de atenuadores registrado, en el corpus español destaca, por el contrario, por el elevado número de intensificadores. En la mitad de los casos este hecho se debe a la utilización de un recurso fraseológico o adverbial, que enfatiza la petición realizada mediante el imperativo.

(47) Haga el favor de retirar su vehículo que estamos recogiendo los restos del incendio y puede resultar peligroso. $(X, 35)$

(48) por favor, ¿me dejas los apuntes de $X$ asignatura? Te los devolveré cuanto antes (VIII, 14)

\section{CONCLUSIONES}

En este trabajo, basado en un proyecto piloto para conocer las diferencias y semejanzas en el uso de las estrategias atenuadoras e intensificadoras por parte de hablantes chinos y españoles, debemos destacar varios aspectos:

En primer lugar, en ambos corpus se constata el hecho de que el recurso de la atenuación se usa con más frecuencia que el de la intensificación, si bien, dado el tipo de acto de habla en el que se incluyen (las peticiones), se trata de un resultado esperable.

En segundo lugar, los informantes chinos utilizaron con mayor frecuencia que sus homólogos españoles el recurso de la atenuación. En cambio, en el recurso de la intensificación ocurrió a la inversa, y en el corpus español se observó mayor frecuencia de uso que en el corpus chino.

En tercer lugar, con respecto a las variables que pueden motivar el mayor o menor uso de estos recursos, en los informantes chinos se observa que a mayor grado de oblicuidad en 
la petición menor uso de recursos atenuadores, y viceversa. En el corpus español, en cambio, se observa cómo el conocimiento de las normas de cortesía de los informantes pudo motivar un elevado uso de dos tipos de recursos atenuadores (modificación temporal del verbo y fórmulas de tratamiento de respeto) en situaciones de asimetría social. Asimismo, cabe destacar cómo, ante una misma situación, diferencias interpretativas, probablemente motivadas por factores socioculturales, produjeron importantes diferencias con respecto al uso de atenuadores por parte de ambos grupos de informantes.

Finalmente, es preciso recordar, tal y como se indicaba en la introducción, la nómina tan exigua de trabajos e investigaciones que sobre pragmática contrastiva chino-español español-chino existen hasta la fecha. Por ello, parece absolutamente necesario continuar la línea de investigación presentada en este trabajo y, en consecuencia, debería plantearse como objetivo a corto medio plazo incrementar la muestra estudiada y el tipo de actos de habla comparados.

\section{REFERENCIAS}

Albelda Marco, Marta (2005): «Discordancia entre atenuación/cortesía e intensificación/descortesía en conversaciones coloquiales", en Blas, J. L, Casanova, M., Velando, M. (eds.): Discurso y Sociedad. Contribuciones al estudio de la lengua en contexto social, Castellón, Universidad de Castellón, 581-590.

AlBELDA MARCO, Marta (2007): La intensificación como categoría pragmática: revisión y propuesta, Frankfurt am Main, Peter Lang.

Albelda Marco, Marta y Ana María Cestero Mancera (2011): «De nuevo, sobre los procedimientos de atenuación lingüística», Español actual: Revista de español vivo, 96, 9-40.

BALlesteros MARTIN, Francisco José (2002): «Mecanismos de atenuación en español e inglés: implicaciones pragmáticas en la cortesía", Círculo de lingüística aplicada a la comunicación, (11). En línea: http://pendientedemigracion.ucm.es/info/circulo/no11/ballesteros.htm (consulta, 11/01/2016)

BLAS ARROYO, José Luis (1994): «Tú y usted: dos pronombres de cortesía en el español actual. Datos de una comunidad peninsular», Estudios de lingüística, 10, 21-44.

BLUM-KULKA, Shoshana y otros (eds.) (1989): Cross-cultural pragmatics: Requests and apologies, Norwood (NJ), Ablex Publishing, 37-70.

BRIz Gómez, Antonio (1998): El español coloquial en la conversación. Esbozo de pragmagramática, Barcelona, Ariel.

BRIZ GÓMEZ, Antonio (2003): «La estrategia atenuadora en la conversación cotidiana española», Bravo, D. (ed.), La perspectiva no etnocentrista de la cortesía: identidad sociocultural de las comunidades hispanohablantes. Actas del I Coloquio Internacional del Programa EDICE, Estocolmo: Programa EDICE, 17-46.

BRIZ GómeZ, Antonio (2007): «Para un análisis semántico, pragmático y sociopragmático de la cortesía atenuadora en España y América», LEA: Lingüística española actual, vol. 29, 1, 5-40.

Cestero Mancera, Ana María y Marta Albelda Marco (2012): «La atenuación lingüística como fenómeno variable», Oralia, 15, 74-124.

CHEN CHI FEN Emily (2001): Making E-Mail Requests to Professors: Taiwanese vs. American Students.http://www2.nkfust.edu.tw/ emchen/Home/Chen\%20Papers/Making\%20email\%20requests\%2 Oto\%20professors.pdf (Fecha de consulta 18/11/2015)

DíAz PÉREZ, Francisco Javier (2003): La Cortesía Verbal en Inglés y en Español: Actos de Habla y Pragmática Intercultural, Jaén, Universidad de Jaén.

ESCANDELL-VIDAL, Ma Victoria (1995): “Cortesía, fórmulas convencionales y estrategias indirectas», Revista Española de Lingüística, 25, 31-66.

ESCANDELL-VIDAL, Ma Victoria (2004): «Aportaciones de la Pragmática», J. Sánchez Lobato e I. Santos Gargallo (dirs.): Enseñar español como segunda lengua o lengua extranjera. Vademécum para la formación de profesores, Madrid, SGEL, 179-198.

GAO HONG (2001): «Features of request strategies in Chinese», Working Papers, Lund University, 47, 73-86.

GRICE, Paul H. (1975): «Logic and Conversation», en Grice, Paul (1989), Studies in the Way of Words, Harvard University Press, 22-40. 
HaVerkATE, Henk (1994): La Cortesía Verbal: Estudio Pragmalingüístico, Madrid, Gredos.

HAVERKATE, Henk (2004): «El análisis de la cortesía comunicativa: Categorización pragmalingüística de la cultura española», D. Bravo y A. Briz (ed.), Pragmática sociocultural, Barcelona, Ariel, 55-66.

Hong Wel (1998): Request Patterns in Chinese and German: A Cross-cultural Study, Munich, Lincom Europa.

HSU TSAI-WEN (2011): Aspectos discursivos en la traducción de la correspondencia comercial chino-español: movimientos retóricos y estrategias de cortesía. Tesis doctoral. Universitat Autònoma de Barcelona. En línea: http://www.tdx.cat/handle/10803/48716 (consulta: 18/11/2015)

HUANG MeI-CHEN (1996): Achieving Cross-cultural Equivalence in a Study of American and Taiwanese Requests. Tesis doctoral. University of Illinois. En línea: https://www.ideals.illinois.edu/handle/2142/20818 (consulta: 18/04/2016)

JIA XUERUI Y HUANG FURONG (2008): «A Contrastive Study of Requests in Chinese and American Cultures», Intercultural Communication Studies, 17, 132-148

LE PAIR, Rob (1996): «Spanish request strategies: A cross-cultural analysis from an intercultural perspective», Language Sciences, 18, 651-670.

LEE-WONG SONG MEI (1994): «Imperatives in requests: Direct or impolite-observations from Chinese», Pragmatics, 4(4), 491-515.

LEE-Wong SONG Mel (1998): «Face support-Chinese particles as mitigators: A study of BA AMA and NE», Pragmatics, 8, 387-404.

LEE-WONG SONG MEI (2000): Politeness and Face in Chinese Culture, Frankfurt am Main, Peter Lang.

LI WEI (2015): "A Sociopragmatic Analysis of Email Requests in Mandarin Chinese and Australian English" en Ko, Leond y Chen Ping (eds.), Translation and Cross-Cultural Communication Studies in the Asia Pacific, Netherlands: Brill.

LI, Charles y Sandra THOMPSON (1989): Mandarin Chinese: A functional reference grammar, California, Univ of California Press.

LIU TZU YU (2012): "Contraste pragmalingüístico de las expresiones de disculpa entre el español y el chino", Pragmalingüística, 20, 256-278.

MARCÉn BOSQUE, Carmen (2001): «Requestive messages in written business communication. A cross-cultural study of British and Spanish correspondence», Palmer; J. C.; Posteguillo; S.; Fortanet, I. (eds.) Discourse analysis and terminology in languages for specific purposes, Castellón, Universitat Jaume I, 217-233.

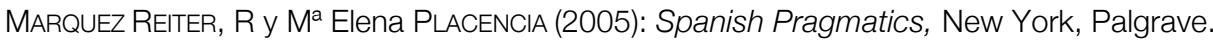

QUEROL BATALLER, María (2016): «Estrategias, alertadores y actos de apoyo en las peticiones en chino y español: esbozo de una comparación», Pragmalingüística, 24, 208-229.

RoviRA-Esteva, Sara (2010): Lengua y escritura chinas. Mitos y realidades, Bellaterra, Barcelona.

ROVIRA-ESTEVA, Sara (2015): "Chinese linguistics in Spain: historical and institutional overview». Encyclopedia of Chinese Language and Linguistics Online. http://referenceworks.brillonline.com/entries/encyclopedia-ofchinese-language-and-linguistics/chinese-linguistics-in-spain-COM_00000075 (consulta 23/11/2015)

RUE Yong-Ju y Zhang Grace QiaO (2008): Request strategies: A comparative study in Mandarin Chinese and Korean, Amsterdam, John Benjamins Publishing.

SÁNCHEZ GRIÑ̃́N, Alberto (2008): Enseñanza y aprendizaje de español como lengua extranjera en China. Retos y posibilidades del enfoque comunicativo. Tesis doctoral. Universidad de Murcia. En línea: http://www.tesisenred.net/handle/10803/10944 (consulta 23/11/2015)

SIEBOLD, Kathrin (2008): Actos de habla y cortesía verbal en español y en alemán. Estudio pragmalingüístico e intercultural, Frankfurt, Peter Lang.

TSUZUKI y otros (2005): «Selection of linguistic forms for requests and offers: Comparison between English and Chinese», Lakoff, R. T., y Ide, S. (eds.), Broadening the horizon of linguistic politeness, Amsterdam, John Benjamins Publishing, 283-298.

WANG SHENGLI (2011): «Request Strategies in Contemporary Chinese Teledramas- A Corpus-based Study», Theory and Practice in Language Studies, 9, 1139-1149.

XU ZENGHUI y ZHOU MINKANG (1997): Gramática china, Barcelona, Universitat Autònoma de Barcelona.

ZHANG YANYIN (1995a): «Strategies in Chinese requesting», Kasper, G. (ed.), Pragmatics of Chinese as Native and target Languages, Honolulu, University of Hawaii, 23-68.

ZHANG YANYIN (1995b): "Indirectness in Chinese requesting», Kasper, G. (ed.), Pragmatics of Chinese as Native and target Languages, Honolulu, University of Hawaii Press, 69-118. 